\title{
THE NATIONAL CATARACT SURGERY SURVEY: II. CLINICAL OUTCOMES
}

\author{
PARUL DESAI \\ London
}

\begin{abstract}
SUMMARY
The short-term clinical outcomes of cataract extraction (within the context of established microsurgical practice) for a sample of all patients undergoing cataract surgery in the United Kingdom in 1990 are presented. Change in best corrected Snellen visual acuity 3 months after surgery and the occurrence of surgically related complications were taken as clinical indicators of outcome. Overall $80 \%(n=764)$ of patients achieved a best corrected postoperative visual acuity of $6 / 12$ or better at 3 months. Surgically related complications occurred in $7 \%(n=71)$ of all patients in the intra-operative period, in $22 \%(n=224)$ in the immediate post-operative period, in $18 \%(n=176)$ at the first post-operative out-patient assessment and in $20 \%(n=200)$ of patients at 3 months after surgery. Coexisting ocular pathology was identified as a risk factor for both poor visual outcome and the occurrence of complications. Increasing severity of ocular pathology was associated with increased risk of poor outcome. These results represent the first national figures for the shortterm clinical outcomes of cataract surgery with respect to the current surgical practice in the United Kingdom.
\end{abstract}

Microsurgical extracapsular techniques for cataract extraction and intraocular lens implantation are now established in ophthalmic surgical practice and routinely available within the National Health Service (NHS). Ninety-four per cent of patients now have cataract surgery performed using these methods. ${ }^{1}$ This paper reports on the short-term clinical outcomes of cataract extraction with respect to current surgical practice for a sample of all patients in the United Kingdom who had cataract surgery in 1990.

\section{METHOD}

The National Cataract Surgery Survey was a prospective cross-sectional survey conducted in 1990 to obtain baseline data on current surgical activity for age-related cataract in the United Kingdom. Consultant ophthalmologists

Correspondence to: Parul Courtney, MSc, FRCS, FCOphth, College of Ophthalmologists, 17 Cornwall Terrace, London NW1 4QW, UK. provided clinical data on NHS patients admitted under their care for cataract surgery during the survey period. Follow-up data were also collected for clinical outcomes 3 months after surgery. The objectives of the survey, data collection and survey methods have been described in detail elsewhere. ${ }^{1}$

Change in best corrected Snellen visual acuity at 3 months post-operatively and the occurrence of surgically related complications were taken as clinical indicators of outcome for cataract extraction. A poor visual outcome was defined as a best corrected visual acuity of less than $6 / 12$ at 3 months post-operatively. The occurrence of clinically evident complications during the surgical procedure, in the immediate post-operative period (within 24 hours of surgery), by the first post-operative out-patient assessment and at 3 months after surgery, were also defined as poor outcome. If more than one type of complication occurred, that which was considered to be the most severe type by the attending ophthalmologist was taken. This was also the case for determining the presence of the most severe, clinically evident co-existing pathology that may have affected visual acuity in the eye having surgery.

The clinical outcomes observed are described first. The 95\% confidence intervals around proportions were calculated by the normal approximation to the binomial distribution for large proportions and by the exact method for smaller ones. ${ }^{2}$ The cumulative incidence is used as a measure of frequency for surgically related complications. This is given by the ratio of the number of patients who developed complications during a given period to the number of patients at the beginning of that period. It indicates the average risk a patient has of developing a complication in the specified period of time.

Multivariate regression analysis methods were then used to determine prognostic factors for poor outcome using the EGRET (Epidemiological Graphics, Estimation and Tabulation) statistical program. A stepwise Poisson regression analysis was first conducted using variables related to process, structure and patient characteristics for visual outcomes and complications separately; these are shown in Table I. 
The variables that demonstrated a significant effect on outcome, having adjusted for all the other variables in the stepwise model, were then used in a regression model together with other possible confounding variables to evaluate their relative risks.

\section{RESULTS}

A total of 1445 patients had surgery performed during the survey period and of these $82 \%$ (1182) had paired records for follow-up data available for assessment of outcomes.

Nine hundred and fifty-nine (81\%) paired records had complete records for visual acuity (on admission, i.e. preoperatively, and at 3 months after surgery) that were available for assessment of visual acuity outcomes. Nine hun-

Table I. Variables used for multivariate analysis

\begin{tabular}{|c|c|}
\hline Variable & Description \\
\hline VISUAL ACUITY & \\
\hline $\begin{array}{l}\text { Structure } \\
\text { Region } \\
\text { Type of hospital } \\
\text { Size of department }\end{array}$ & $\begin{array}{l}\text { Coded } 1 \text { to } 19 \\
\text { Teaching, Eye, District } \\
\leqslant 2,3,4,>4 \text { consultants }\end{array}$ \\
\hline $\begin{array}{l}\text { Process } \\
\text { Type of admission } \\
\text { Type of anaesthetic } \\
\text { Grade of surgeon } \\
\text { Complications at } 3 \text { months } \\
\text { Capsulotomy indicated } \\
\text { Final refraction performed } \\
\text { Spectacles dispensed } \\
\text { Waiting time for admission }\end{array}$ & $\begin{array}{l}\text { In-patient or Day-case } \\
\text { General or Local } \\
\text { Consultant, SR, Reg., SHO, other }\end{array}$ \\
\hline $\begin{array}{l}\text { Patient characteristics } \\
\text { Age (years) } \\
\text { Sex } \\
\text { Visual acuity on admission } \\
\text { Coexisting ocular pathology }\end{array}$ & $\begin{array}{l}\text { Mild to moderate } \\
\text { Drusen or RPE changes at the macula } \\
\text { Background diabetic retinopathy } \\
\text { Severe } \\
\text { Disciform macular degeneration } \\
\text { Diabetic maculopathy } \\
\text { Proliferative diabetic retinopathy } \\
\text { Glaucoma } \\
\text { Amblyopia }\end{array}$ \\
\hline COMPLICATIONS & \\
\hline $\begin{array}{l}\text { Structure } \\
\text { Region } \\
\text { Type of hospital } \\
\text { Size of department }\end{array}$ & $\begin{array}{l}\text { Coded } 1 \text { to } 19 \\
\text { Teaching, Eye, District } \\
\leqslant 2,3,4,>4 \text { consultants }\end{array}$ \\
\hline $\begin{array}{l}\text { Process } \\
\text { Type of admission } \\
\text { Type of anaesthetic } \\
\text { Grade of surgeon }\end{array}$ & $\begin{array}{l}\text { In-patient or Day-case } \\
\text { General or Local } \\
\text { Consultant, SR, Reg., SHO, other }\end{array}$ \\
\hline $\begin{array}{l}\text { Patient characteristics } \\
\text { Age (years) } \\
\text { Sex } \\
\text { Visual acuity on admission } \\
\text { Coexisting ocular pathology }\end{array}$ & $\begin{array}{l}\text { Mild to moderate } \\
\text { Drusen or RPE changes at the macula } \\
\text { Background diabetic retinopathy } \\
\text { Severe } \\
\text { Disciform macular degeneration } \\
\text { Diabetic maculopathy } \\
\text { Proliferative diabetic retinopathy } \\
\text { Glaucoma } \\
\text { Amblyopia }\end{array}$ \\
\hline
\end{tabular}

RPE, retinal pigment épithelium. dred and ninety-eight (84\%) paired records had complete records for complications occurring during the surgical procedure, in the immediate post-operative period and at 3 months that were available for analysis.

\section{Visual Acuity}

The distribution of visual acuity in the eye having surgery, on admission and its change at 3 months post-operatively, is shown in Table II. Visual acuity was grouped as adequate if $6 / 6$ to $6 / 12$, low- 1 if it was $6 / 18$ to $6 / 24$, low- 2 if $6 / 36$ to $6 / 60$, and blind if it was $3 / 60$ or less. Preoperatively, a small proportion of patients $(8 \%, n=80)$ had good visual acuity, $51 \%(n=489)$ had significant visual impairment with a visual acuity of $6 / 18$ to $6 / 60$ and $41 \%$ ( $n=390$ ) of all patients had visual acuity of $3 / 60$ or less. By 3 months post-operatively this distribution shifts to the opposite direction, with about $80 \%$ of all patients achieving a good visual outcome with acuity of $6 / 12$ or better. Of the $20 \%$ who had poor visual outcome, $4 \%$ had visual acuity of $3 / 60$ or less and $16 \%$ had visual acuity ranging from $6 / 18$ to $6 / 60$.

Irrespective of the pre-operative visual acuity the vast majority of patients managed to achieve a good visual result, as seen in Table II. The shaded cells represent the proportion of patients in each pre-operative group whose post-operative vision fell in a category worse than that on admission. Table III shows a more detailed breakdown of the change in pre-operative vision by 3 months post-operatively.

If only patients with no other ocular pathology $(n=537)$ are considered then $90 \%(n=485)$ of them achieve a good visual outcome of $6 / 12$ or better at 3 months after surgery. Approximately one third (36\%) of patients had some coexisting ocular pathology present in the eye that had surgery (Table IV). The 'other' category included a wide variety of conditions consisting of the following: predominantly corneal pathology (scarring secondary to infections/inflammations, dystrophies) and common lid disorders, with a few retinal degenerations, vasculopathies and old retinal detachments.

The results of multivariate regression analysis are presented in Table V. Interactions between age, sex, coexisting ocular pathology and the occurrence of complications were all examined but were not found to exert any statistically significant effect.

Increasing severity of co-existing ocular pathology was associated with increasing risk of poor visual outcome having adjusted for all the other variables in the model. The presence of mild to moderate pathology was associated with a relative risk of 2.7 (95\% CI 1.7 to 4.2$)$ and severe ocular pathology had a relative risk of $4.2(95 \% \mathrm{CI}$ 1.3 to 2.8 ). Females were at greater risk of poor outcome, relative risk 1.5 (95\% CI 1.04 to 2.25 ). The occurrence of any complication at 3 months after surgery was associated with an increased risk of poor visual outcome (relative risk. $1.89,95 \%$ CI 1.27 to 2.8 ). Patients in whom a capsulo- 
Table II. Change in distribution of visual acuity at 3 months post-operatively, in patients grouped according to vision on admission

\begin{tabular}{|c|c|c|c|c|c|c|c|}
\hline \multirow{2}{*}{$\begin{array}{l}\text { Visual acuity } \\
\text { on admission }\end{array}$} & & \multirow{2}{*}{$\begin{array}{l}\text { No. of } \\
\text { patients }\end{array}$} & \multirow[b]{2}{*}{$\%$} & \multicolumn{4}{|c|}{ Visual acuity at 3 months post-op. } \\
\hline & & & & Adequate & Low-1 & Low-2 & Blind \\
\hline $6 / 6-6 / 12$ & Adequate & 80 & 8.34 & $85 \%$ & $11 \%$ & $4 \%$ & $0 \%$ \\
\hline $6 / 18-6 / 24$ & Low-1 & 253 & 26.38 & $87 \%$ & $9 \%$ & $3 \%$ & $1 \%$ \\
\hline $6 / 36-6 / 60$ & Low-2 & 236 & 24.61 & $80 \%$ & $13 \%$ & $5 \%$ & $2 \%$ \\
\hline \multirow[t]{2}{*}{ 3/60-HM } & Blind & 390 & 40.67 & $74 \%$ & $12 \%$ & $7 \%$ & $8 \%$ \\
\hline & All & 959 & 100.00 & $79.67 \%$ & $11.37 \%$ & $5.21 \%$ & $3.75 \%$ \\
\hline
\end{tabular}

HM, hand movements.

Shaded cells indicate poor outcome ( 3 months post-operative vision worse than that on admission).

tomy was indicated also had a higher risk of poor visual outcome (relative risk $1.98,95 \%$ CI 1.2 to 3.27 ).

\section{Surgically Related Complications}

Seven per cent $(n=71)$ of all patients had some complication occurring during the intra-operative period, $22 \%$ $(n=224)$ had some type of immediate post-operative complication, and $18 \%(n=176)$ had some surgically related complication at the first post-operative out-patient assessment. At 3 months after surgery $20 \%(n=200)$ of patients had some complication present. Eleven per cent $(n=11)$ of patients experienced some type of complication at all times from the intra-operative period to 3 months after surgery.

In the intra-operative period $4 \%(n=39)$ of all patients had capsule rupture without vitreous loss, a further $1 \%$ $(n=11)$ had capsule rupture associated with vitreous loss, $0.1 \%(n=1)$ had a retrobulbar haemorrhage resulting from a retrobulbar block and $2 \%$ had some other type of complication.
The types of complications occurring in the immediate post-operative period, by the first assessment in the outpatient department and at 3 months after surgery are shown in Table VI. The types of complications seen in the immediate post-operative period consist predominantly of corneal oedema and raised intraocular pressure, followed by wound leak and hyphaema. These gradually resolved so that at 3 months after surgery the predominant complication was posterior capsule thickening $(6.3 \%)$, followed by raised intraocular pressure $(2.3 \%)$ and presence of clinically detectable cystoid macular oedema.

The cumulative incidence of clinically detectable cystoid macular oedema by 3 months post-operatively (which may or may not have been confirmed by fluoroscein angiography) was $1.2 \%(n=12)$. These patients had good post-operative visual acuity of $6 / 12$ or better in $75 \%$ of cases $(n=8)$. Three of these patients had a capsule rupture during surgery, one of which was associated with vitreous loss.

Of all patients, $0.3 \%(n=3)$ had endophthalmitis within

Table III. Detailed breakdown of changes in vision at 3 months after cataract surgery

\begin{tabular}{|c|c|c|c|c|c|c|c|c|c|c|c|c|}
\hline \multirow{2}{*}{$\begin{array}{l}\text { Visual acuity } \\
\text { on admission }\end{array}$} & & \multirow[b]{2}{*}{ Total } & \multicolumn{10}{|c|}{ Visual acuity 3 months after cataract surgery } \\
\hline & & & $6 / 6$ & $6 / 9$ & $6 / 12$ & $6 / 18$ & $6 / 24$ & $6 / 36$ & $6 / 60$ & $3 / 60$ & $\mathrm{CF}$ & HM \\
\hline \multirow[t]{2}{*}{$6 / 6$} & Number & 4 & 3 & & & & & & 1 & & & \\
\hline & $\%$ & $100 \%$ & $75 \%$ & & & & & & $25 \%$ & & & \\
\hline \multirow[t]{2}{*}{$6 / 9$} & Number & 30 & 16 & 8 & & 3 & 3 & & & & & \\
\hline & $\%$ & $100 \%$ & $53 \%$ & $27 \%$ & & $10 \%$ & $10 \%$ & & & & & \\
\hline \multirow[t]{2}{*}{$6 / 12$} & Number & 46 & 16 & 16 & 9 & 2 & 1 & 2 & & & & \\
\hline & $\%$ & $100 \%$ & $35 \%$ & $35 \%$ & $20 \%$ & $4 \%$ & $2 \%$ & $4 \%$ & & & & \\
\hline \multirow[t]{2}{*}{$6 / 18$} & Number & 129 & 52 & 36 & 21 & 11 & 3 & 3 & 3 & & & \\
\hline & $\%$ & $100 \%$ & $40 \%$ & $28 \%$ & $16 \%$ & $9 \%$ & $2 \%$ & $2 \%$ & $2 \%$ & & & \\
\hline \multirow[t]{2}{*}{$6 / 24$} & Number & 124 & 42 & 50 & 19 & 7 & 3 & 1 & & & 2 & \\
\hline & $\%$ & $100 \%$ & $34 \%$ & $40 \%$ & $15 \%$ & $6 \%$ & $2 \%$ & $1 \%$ & & & $2 \%$ & \\
\hline \multirow[t]{2}{*}{$6 / 36$} & Number & 129 & 38 & 45 & 23 & 13 & 4 & 4 & 2 & & & \\
\hline & $\%$ & $100 \%$ & $29 \%$ & $35 \%$ & $18 \%$ & $10 \%$ & $3 \%$ & $3 \%$ & $2 \%$ & & & \\
\hline \multirow[t]{2}{*}{$6 / 60$} & Number & 107 & 32 & 32 & 19 & 10 & 4 & 1 & 5 & 1 & 3 & \\
\hline & $\%$ & $100 \%$ & $30 \%$ & $30 \%$ & $18 \%$ & $9 \%$ & $4 \%$ & $1 \%$ & $5 \%$ & $1 \%$ & $3 \%$ & \\
\hline \multirow[t]{2}{*}{$3 / 60$} & Number & 36 & 8 & 9 & 8 & 2 & 1 & & 5 & 1 & 2 & \\
\hline & $\%$ & $100 \%$ & $22 \%$ & $25 \%$ & $22 \%$ & $6 \%$ & $3 \%$ & $\cdot$ & $14 \%$ & $3 \%$ & $6 \%$ & \\
\hline \multirow[t]{2}{*}{$\mathrm{CF}$} & Number & 209 & 56 & 63 & 37 & 20 & 8 & 3 & 7 & 2 & 11 & 2 \\
\hline & $\%$ & $100 \%$ & $27 \%$ & $30 \%$ & $18 \%$ & $10 \%$ & $4 \%$ & $1 \%$ & $3 \%$ & $1 \%$ & $5 \%$ & $1 \%$ \\
\hline \multirow[t]{2}{*}{ HM } & Number & 145 & 33 & 52 & 21 & 10 & 4 & 6 & 7 & 2 & 6 & 4 \\
\hline & $\%$ & $100 \%$ & $23 \%$ & $36 \%$ & $14 \%$ & $7 \%$ & $3 \%$ & $4 \%$ & $5 \%$ & $1 \%$ & $4 \%$ & $3 \%$ \\
\hline \multirow{2}{*}{ All } & Number & 959 & 296 & 311 & 157 & 78 & 31 & 20 & 30 & 6 & 24 & 6 \\
\hline & $\%$ & $100 \%$ & $31 \%$ & $32 \%$ & $16 \%$ & $8 \%$ & $3 \%$ & $2 \%$ & $3 \%$ & $1 \%$ & $3 \%$ & $1 \%$ \\
\hline
\end{tabular}

$\mathrm{CF}$, counting fingers; HM, hand movements. 
Table IV. Co-existing ocular pathology in eye having surgery

\begin{tabular}{lcc}
\hline Type of pathology & $n$ & $\%$ \\
\hline None & 537 & 63.6 \\
Age-related maculopathy & 84 & 10 \\
Drusen/RPE changes & $(80)$ & \\
Disciform & $(4)$ & \\
Diabetic retinopathy & 29 & 3.4 \\
Background & $(15)$ & \\
Proliferative & $(6)$ & \\
Maculopathy & $(8)$ & 10.7 \\
Glaucoma & 90 & 1.5 \\
Amblyopia & 13 & 10.9 \\
Other & 92 & 100 \\
*Total & $845^{\mathrm{a}}$ & \\
\hline
\end{tabular}

RPE, retinal pigment epithelium.

${ }^{a}$ For 114 patients this information was not available.

1 month of surgery. The definition of endophthalmitis used in the survey did not distinguish between cultureproven and sterile endophthalmitis. One patient had a retinal detachment $(0.1 \%)$ occurring within 3 months of surgery (extracapsular extraction with posterior chamber lens implant).

The cumulative incidence of the major surgically related complications are given in Table VII.

The results of multivariate regression analysis for risk factors for occurrence of surgically related complications are presented in Table VIII. The presence of co-existing ocular pathology was found to be associated with increased risk in all the post-operative periods having adjusted for age, sex and grade of surgeon. Increasing severity of ocular pathology was associated with increased risk.

No risk factors for intra-operative complications were identified in this sample of patients. The presence of mild to moderate ocular pathology was associated with a relative risk of 1.59 (95\% CI 1.13 to 2.23) and severe ocular pathology was associated with a relative risk of 2.07 (95\% CI 1.44 to 2.99) for the occurrence of a complication in the
Table V. Risk factors for poor visual outcome at 3 months after surgery

\begin{tabular}{lccc}
\hline Variable & Relative risk & $95 \%$ CI & $p$ \\
\hline $\begin{array}{l}\text { Ocular pathology } \\
\text { (mild to moderate) }\end{array}$ & 2.76 & 1.79 to 4.25 & $<0.001$ \\
$\begin{array}{l}\text { Ocular pathology } \\
\quad(\text { severe) }\end{array}$ & 4.28 & 2.8 to 6.56 & $<0.001$ \\
$\begin{array}{l}\text { Complications at } \\
\quad 3 \text { months }\end{array}$ & 1.89 & 1.27 to 2.8 & 0.002 \\
Capsulotomy indicated & 1.98 & 1.20 to 3.27 & 0.007 \\
Sex: female & 1.53 & 1.04 to 2.25 & 0.031 \\
\hline
\end{tabular}

Age adjusted; $n=738$; Poisson regression model.

immediate post-operative period. The occurrence of complications at 3 months was associated with a relative risk of 1.6 for the presence of mild to moderate pathology. The presence of severe pathology was also associated with a relative risk of 1.6 for complications at this time.

Neither the region, type of hospital, size of ophthalmic department, type of admission, type of anaesthetic nor grade of surgeon performing the operation was observed to influence short-term clinical outcome (post-operative visual acuity and surgically related complications) in this sample of patients.

\section{DISCUSSION}

Cataract surgery improves visual acuity in the majority of patients undergoing the procedure. Twenty per cent $(n=195)$ of patients were not able to obtain a post-operative acuity of $6 / 12$ or better. Ten per cent $(n=19)$ of these patients with poor visual outcome did not have any coexisting ocular pathology, had not had a final refraction and not had spectacles dispensed. It is possible that in these cases there may be some potential for improvement in visual status when spectacles are provided.

About half of the patients $(n=182)$ admitted for surgery with a best corrected visual acuity of $3 / 60$ or less had no other ocular pathology present. Thus 1 in 5 of all patients

Table VI. Complications of surgery

\begin{tabular}{|c|c|c|c|c|c|c|}
\hline \multirow[b]{2}{*}{ Type of complication } & \multicolumn{2}{|c|}{$\begin{array}{c}\text { Immediate } \\
\text { (within } 24 \text { hours) }\end{array}$} & \multicolumn{2}{|c|}{$\begin{array}{l}\text { 1st out-patient visit } \\
\text { (within } 1 \text { month) }\end{array}$} & \multicolumn{2}{|c|}{ At 3 months } \\
\hline & $n$ & $\%$ & $n$ & $\%$ & $n$ & $\%$ \\
\hline None & 774 & 77.6 & 822 & 82.4 & 798 & 80 \\
\hline Corneal oedema & 96 & 9.6 & 32 & 3.2 & 4 & 0.4 \\
\hline Raised IOP & 53 & 5.3 & 33 & 3.3 & 23 & 2.3 \\
\hline Wound leak & 18 & 1.8 & 8 & 0.8 & 2 & 0.2 \\
\hline Iris prolapse & 3 & 0.3 & 2 & 0.2 & 2 & 0.2 \\
\hline Ext. infection & 1 & 0.1 & 2 & 0.2 & 2 & 0.2 \\
\hline Endophthalmitis & 1 & 0.1 & 2 & 0.2 & 0 & 0 \\
\hline Dislocated IOL & 0 & 0 & 0 & 0 & 3 & 0.3 \\
\hline Hyphaema & 13 & 1.3 & 4 & 0.4 & 0 & 0 \\
\hline Uveitis & 14 & 1.4 & 21 & 2.1 & 11 & 1.1 \\
\hline Retinal detachment & 0 & 0 & 0 & 0 & 1 & 0.1 \\
\hline Cystoid macular oedema & 0 & 0 & 0 & 0 & 12 & 1.2 \\
\hline Soft lens matter & 0 & 0 & 0 & 0 & 3 & 0.3 \\
\hline Post. capsule thickening & 0 & 0 & 0 & 0 & 63 & 6.3 \\
\hline Other $\mathrm{r}^{\mathrm{a}}$ & 25 & 2.5 & 72 & 7.2 & 74 & 7.4 \\
\hline All & 998 & 100 & 998 & 100 & 998 & 100 \\
\hline
\end{tabular}

IOP, intraocular pressure; IOL, intraocular lens.

a‘Other' includes: sphincter tear, irregular or peaked pupil, iris tuck, wound dehiscence, tear or folds in Descemet's membrane. 
Table VII. Cumulative incidence of surgically related complications

\begin{tabular}{lccc}
\hline Type of complication & $\begin{array}{c}\text { No. with } \\
\text { complication }\end{array}$ & $\begin{array}{c}\text { Cumulative } \\
\text { incidence (\%) }\end{array}$ & 95\% CI \\
\hline $\begin{array}{l}\text { Intra-operative period } \\
\text { Capsule rupture }\end{array}$ & 39 & 3.9 & 2.79 to 5.30 \\
$\begin{array}{l}\text { Capsule rupture and } \\
\text { vitreous loss }\end{array}$ & 11 & 1.1 & 0.56 to 1.96 \\
$\begin{array}{l}\text { Within 1 month } \\
\begin{array}{l}\text { External infection } \\
\text { Endophthalmitis }\end{array}\end{array}$ & 4 & 0.4 & 0.1 to 1.2 \\
$\begin{array}{l}\text { At 3 months } \\
\text { Dislocated IOL }\end{array}$ & 3 & 0.3 & 0.07 to 0.87 \\
$\begin{array}{l}\text { Retinal detachment } \\
\text { Cystoid macular oedema }\end{array}$ & 12 & 0.3 & 0.07 to 0.87 \\
Post. capsule thickening & 63 & 0.1 & 0.006 to 0.55 \\
\hline
\end{tabular}

IOL, intraocular lens.

were admitted for surgery for blinding cataract. This was not associated with long waiting times for surgery or with second eye surgery. Since $90 \%$ of them were able to achieve a good visual outcome by 3 months, further investigation into the reasons for their late presentation is required.

A fifth of all patients experience some surgically related complication in the immediate post-operative period and a fifth at 3 months after surgery. The survey was not designed to examine the complex relationship between surgical technique and the occurrence of complications, but from the nature of the types of complications occurring at these times it is possible that improvements in surgical technique will have some influence on the frequency of their occurrence.

Both endophthalmitis ${ }^{3-5}$ and retinal detachment (within 6 months of surgery ${ }^{6}$ are rare events following cataract surgery. Although the cumulative incidence for retinal detachment is lower and that for endophthalmitis is higher than in other comparable reports, the wide and overlapping confidence intervals preclude the detection of any real differences and it is not possible to conclude that our experience is either better or worse (Table IX).

There were $6.3 \%$ ( $n=63$ ) of patients with posterior capsule thickening by 3 months after surgery and capsulotomy was indicated in $36(59 \%)$ of these. An earlier surgical audit conducted in a single ophthalmic department during a period of changing surgical practices from intracapsular to extracapsular surgery with intraocular

Table VIII. Risk factors for complications of surgery

\begin{tabular}{lccr}
\hline Variable & Relative risk & $95 \%$ CI & \multicolumn{1}{c}{$p$} \\
\hline $\begin{array}{l}\text { Immediate post-operative period } \\
\text { Ocular pathology }\end{array}$ & & \\
$\quad$ (mild to moderate) & 1.59 & 1.13 to 2.23 & 0.007 \\
$\begin{array}{l}\text { Ocular pathology (severe) } \\
\text { At } 3 \text { months }\end{array}$ & 2.07 & 1.44 to 2.99 & $<0.001$ \\
$\begin{array}{l}\text { Ocular pathology } \\
\quad \text { (mild to moderate) }\end{array}$ & 1.6 & 1.14 to 2.24 & \\
$\begin{array}{l}\text { Ocular pathology (severe) } \\
\text { Ond }\end{array}$ & 1.57 & 1.04 to 2.37 & 0.006 \\
\hline
\end{tabular}

Adjusted for age, sex and grade of surgeon; $n=881$; Poisson regression model.
Table IX. Endophthalmitis and retinal detachment after cataract surgery

\begin{tabular}{|c|c|c|c|}
\hline Complication & Sample size & $\%$ & $95 \% \mathrm{CI}$ \\
\hline \multicolumn{4}{|c|}{ Endophthalmitis } \\
\hline \multicolumn{4}{|c|}{ National Cataract Surgery } \\
\hline Stark et al. ${ }^{3}$ & 8597 & 0.1 & 0.04 to 0.16 \\
\hline Kattan et al. ${ }^{4}$ & 23625 & 0.072 & 0.043 to 0.12 \\
\hline Javitt et al. ${ }^{5}$ & 224061 & 0.085 & 0.075 to 0.095 \\
\hline \multicolumn{4}{|c|}{ Retinal detachment } \\
\hline Survey & 998 & 0.1 & 0.006 to 0.55 \\
\hline Smith et al. ${ }^{6}$ & 3065 & 0.62 & 0.37 to 0.97 \\
\hline
\end{tabular}

lens implantation reported $13 \%$ of patients having posterior capsule thickening by 3 months post-operatively. ${ }^{7}$ It has been estimated that within the NHS about 105.090 operations are performed annually for age-related cataract in the United Kingdom. ${ }^{1}$ From this estimate, about 6621 patients annually will have posterior capsular thickening by 3 months after surgery and at least 3906 of them will have been identified as needing a capsulotomy at that time. This must be considered to be a minimum estimate of the number of patients who will eventually need a capsulotomy as this figure will most certainly rise with longer follow-up.

Capsulotomy is now usually performed as a secondary procedure with the YAG laser and is associated with certain risks. Cystoid macular oedema is recognised as a complication of capsulotomy, ${ }^{8,9}$ but a recent study on the long-term effect of YAG capsulotomy suggests that this procedure may increase the risk for retinal detachment. ${ }^{10}$ This, together with the resource and cost implications of performing a capsulotomy, must be considered when planning and providing a comprehensive cataract service.

It is not clinically or biologically surprising to find that co-existing ocular pathology is a risk factor for both poor visual outcome and the occurrence of complications. No adequate explanation was found for the higher relative risk of poor visual outcome seen in females having adjusted for all the other variables in the model including age on admission for surgery.

Regional variations for surgical outcome were not demonstrated. However, the survey was not designed for this purpose and it is possible that any small differences that may have occurred would not have been detected.

These results from a representative sample of patients ${ }^{1}$ reflect a national level of the quality of medical care provided within the NHS for patients having surgery for agerelated cataract, in the context of established microsurgical practice with intraocular lens implantation (care being measured in terms of the clinical outcomes studied in the survey). For the first time national figures for shortterm clinical outcomes of cataract surgery are provided and these may be particularly useful for local, district or regional audit. By identifying risk factors and quantifying the level of risk involved it will be possible to advise patients better on the outcome of cataract surgery. 
I am grateful to all the ophthalmologists who participated in the Survey and without whose support it would not have been possible; the Audit Committee, Miss Mahmood and the staff of the College of Ophthalmologists. The Department of Health provided core funding for this project.

Key words: Cataract surgery, Complications, Outcome, Visual acuity.

\section{REFERENCES}

1. Courtney P. The National Cataract Surgery Survey. I. Methods and descriptive features. Eye 1992;6:487-92.

2. Gardner SB, Winter PD, Gardner MJ. Confidence interval analysis. London:BMJ,1989.

3. Stark WJ, Worthen DA, Holladay JT, Bath P, et al. The FDA report on intraocular lenses. Ophthalmology 1983;90: 311-7.

4. Kattan HM, Flynn HW, Pflugelder SC, Robertson C, Forster RK. Nosocomial endophthalmitis survey: current incidence of infection after intraocular surgery. Ophthalmology 1991;98:227-38.

5. JavittJC, Vitale S, Canner JK, Street DA, et al. National out- comes of cataract extraction: endophthalmitis following inpatient surgery. Arch Ophthalmol 1991;109:1085-9.

6. Smith PW, Stark WJ, Maumenee AE, Enger CL, et al. Retinal detachment after extracapsular cataract extraction with posterior chamber intraocular lens. Ophthalmology 1987; 94:495-504.

7. Acheson JF, McHugh JD, Falcon MG. Changing patterns of early complications in cataract surgery with new techniques: a surgical audit. Br J Ophthalmol 1988;72:481-4.

8. Wright PL, Wilkinson CP, Hal D, Balyeat MD, Popham J, Reinke M. Angiographic cystoid macular oedema after posterior chamber lens implantation. Arch Ophthalmol 1988;106:740-4.

9. Kraff CM, Sanders DR, Jampol LM, Lieberman HL. Effect of primary capsulotomy with extracapsular surgery on the incidence of pseudophakic cystoid macular oedema. Am J Ophthalmol 1984;98:166-70.

10. Javitt JC, Tielsch JM, Canner JK, Kolb MM, Sommer A, Steinberg EP. National outcomes of cataract extraction: increased risk of retinal complications associated with Nd:YAG laser capsulotomy. Ophthalmology 1992;99: 1487-98. 